\title{
Solunum Fonksiyon Testinde FEF Saptanan Hastaların Polikliniğe Başvuru Nedenlerinin Değerlendirilmesi ve KOAH'ın Erken Teşhisindeki Önemi
}

Evaluation of the Reasons for Applying to Clinic of Outpatients with A Low FEF25-75\% in the Pulmonary Function Test and Its Importance in Early Diagnosis of COPD

\author{
${ }^{1}$ Şenay Yılmaz, ${ }^{1}$ Sümeyye Nur Aslan Küçükyurt, ${ }^{2}$ Kevser Setenay Dinçer Öner, \\ ${ }^{1}$ Mehmet Sinan Erginel
}

${ }^{1}$ Eskişehir Osmangazi Üniversitesi Tip Fakültesi, Gögüs Hastalıkları Anabilim Dalı, Eskișehir, Türkiye

${ }^{2}$ Eskişehir Osmangazi Üniversitesi Tip Fakültesi, Biyoistatistik Anabilim Dalı, Eskisehir, Türkiye

\section{Correspondence:}

Senay YILMAZ

Eskişehir Osmangazi Üniversitesi Tip Fakültesi, Göğüs Hastalıkları

Anabilim Dalı, Eskișehir, Türkiye e-mail: senayyilmazesogu@gmail. com

\section{Ozet}

Vital kapasitenin \%25-\%75 arasındaki zorlu ekspiratuar akım $\left(\mathrm{FEF}_{0255}\right)$ küçük hava yolu hastalığ $(\mathrm{KHH})$ 'nın değerlendirilmesinde kullanılan solunum fonksiyon testi (SFT) parametresidir. Çalışmamızda, göğüs hastalıkları polikliniğine başvuru yapan $\mathrm{FEF}_{\% 225-75}$ düşüklüğü saptanan hastaların polikliniğe bașvuru nedenleri, $\mathrm{FEF}_{025-75}$ 'in kronik obstrüktif akciğer hastalığ 1 (KOAH)'ın erken teșhisine katkısı ve risk faktörlerine yönelik erken müdahalenin önemini vurgulamak amaçlanmıștır. Calıșmaya Ocak 2020Nisan 2021 tarihleri arasında ESOGÜ göğüs hastalıkları polikliniğine başvuru yapan kabul edilebilir SFT’si olan 381 hasta alındı. İstatistiksel analizler için ShapiroWilk, Mann-Whitney U ve Kikare testi kullanıldı. p $<0.05$ istatistiksel anlamlı kabul

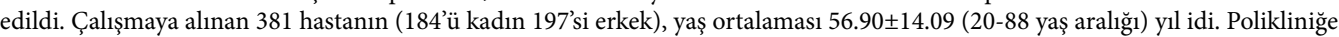
başvuru nedenleri 'kontrol başvuru', 'ilk başvuru', 'sağllk raporu' ve 'preoperatif değerlendirme' olarak 4 grupta, $\mathrm{KHH} \mathrm{ise}_{\mathrm{FEF}} \mathrm{F}_{025-75}$ $<65$ olarak tanımlandı. İleri yaș ( $\geq 50$ yaş), sigara içme, komorbid hastalık öyküsü ve nefes darlığı semptomu ile KHH arasında anlamlı ilişki saptandı $(\mathrm{p}<0.05)$. Cinsiyet, vücut kitle indeksi (VKİ) ve geçirilmiş akciğer hastalığı açısından gruplar arasında fark saptanmadı ( $p>0.05)$. Sigara içme, komorbid hastalık, geçirilmiş hastalık öyküsü ve bașvuru semptomları ile başvuru nedenleri arasında istatistiksel olarak anlamlı ilişki gözlendi $(\mathrm{p}<0.05)$. Sigara içen erkeklerde kadınlara göre $\mathrm{FEF}_{0625-75}$ anlamlı düşük idi $(\mathrm{p}=0.022)$. İleri yaş, sigara içiciliği, komorbid hastalık öyküsü ile nefes darlığı semptomu, KHH ile anlamlı ilişkili iken, KHH sigara içen erkeklerde kadınlara göre daha yüksek idi. Bu faktörlerin klinisyenler tarafından dikkate alınması ilk başvuru yapan hastalarda gerek obstrüktif hastalıkların erken teşhisinde gerekse hastalığın seyri ve tedavi edilmesinde yol gösterici olan $\mathrm{FEF}_{0 / 25-75}$ 'in değerlendirilmesi ve hedefe yönelik tedavilerin geliştirilmesi açısından önem taşımaktadır.

Anahtar Kelimeler: küçük hava yolu hastalığı, $\mathrm{FEF}_{q_{225-75}}$, solunum fonksiyon testi, kronik obstrüktif akciğger hastalı̆̆

\section{Abstract}

Forced expiratory flow $\left(\mathrm{FEF}_{25-75 \%}\right)$ between $25 \%-75 \%$ of vital capacity is the pulmonary function test (PFT) parameter used in the evaluation of small airway disease (SAD).In our study, we aimed to emphasize the reasons for the admission of patients with a low FEF who applied to the pulmonary diseases polyclinic, the contribution of FEF to the early diagnosis of chronic obstructive pulmonary disease (COPD), and the importance of early intervention for risk factors. The study included 381 patients with acceptable PFT who applied to the ESOGU pulmonary diseases polyclinic between January 2020 and April 2021.ShapiroWilk, Mann-Whitney U and Chi-square tests were used for statistical analysis. $p<0.05$ was considered statistically significant. The mean age of 381 patients (184 females and 197 males) included in the study was 56.90土14.09 years (range 20-88 years).The reasons for applying to the polyclinic were defined in 4 groups as 'control application', 'first application', 'health report' and 'preoperative evaluation', and SAD was defined as $\mathrm{FEF}_{2575 \%}<65$. A significant correlation was found between advanced age ( $\geq 50$ years), smoking, history of comorbid disease, and symptoms of dyspnea and SAD $(\mathrm{p}<0.05)$. There was no difference between the groups in terms of gender, BMI and previous lung disease $(\mathrm{p}>0.05)$. A statistically significant correlation was observed between smoking, comorbid disease, previous disease history, and admission symptoms and reasons for admission $(\mathrm{p}<0.05) . \mathrm{FEF}_{25-75 \%}$ was significantly lower in smoking men compared to women $(\mathrm{p}=0.022)$. SAD was higher in men smokers than in women, while advanced age, smoking, history of comorbid disease and symptoms of dyspnea were significantly associated with SAD.Consideration of these factors by clinicians is important for the evaluation of $\mathrm{FEF}_{25-75 \%}$, which guides both the early diagnosis of obstructive diseases and the course and treatment of the disease, and the development of targeted therapies.

Keywords: small airway disease, $\mathrm{FEF}_{25-75 \%}$, pulmonary functional test, chronic obstructive pulmonary disease

Received 16.06.2021 Accepted 09.07.2021 Online published 09.07.2021 


\section{Giriş}

Kronik obstrüktif akciğer hastalığı (KOAH) önlenebilir ve tedavi edilebilir kronik havayolu hastalığıdır ve dünya çapında önde gelen ölüm nedenlerinden biridir (1). Solunum fonksiyon testi (SFT) KOAH tanısinda altın standart olmasının yanısıra kullanımı pratik ve güvenli bir testtir. SFT' de postbronkodilatör ölçümde birinci saniyede zorlu ekspiratuar hacim $\left(\mathrm{FEV}_{1}\right)$ / zorlu vital kapasite (FVC) oranının \%70'in altında olması obstrüktif akciğer hastalıkları için tanı koydurabilmektedir (2-4).

Klinik pratikte sigara içen ve solunum semptomları olan ancak SFT sonuçları normal olan hastalarla karşılaşmaktayız. $\mathrm{Bu}$ hastalarda küçük hava yollarında obstrüksiyonun saptanması yüksek riskli bireyler arasında KOAH gelişimi için erken öngörücü bir belirteç olabilir (5). Normal $\mathrm{FEV}_{1}$ ve Karbonmonoksit Difüzyon Kapasitesi Ölçümü (DLCO) değerleri olan hastalarda vital kapasitenin \%25-\%75 arasındaki zorlu ekspiratuar akım $\left(\mathrm{FEF}_{\% 25-75}\right)$ değerlerinin düşüklüğünün saptanması birincil hava akımı tıkanıklığının ortaya çıktığı periferik hava yollarında hava akımının hassas bir belirtecidir. $\mathrm{FEF}_{\% 25-75}$ küçük hava yolu hastalığı (KHH) ile ilişkili erken bronşiyal bozuklukla seyreden hastalıkların tespitinde yol gösterici olabilmektedir $(6,7)$. Bu nedenle $\mathrm{FEF}_{\% 25-75}$, KOAH için $\mathrm{FEV}_{1}$, DLCO ve FVC gibi diğer belirteçlere göre daha erken bir belirteç olabilir.

Sigara içimi de KOAH'ın temel bir özelliği olan KHH'nın gelişimi için en önemli risk faktörü olarak kabul edilmektedir (5). Bu hastaları sigarayı birakmak konusunda uyarmak bile ileride gelişebilecek KOAH'1 önlemede önemli bir basamak olacaktır. Düşük $\mathrm{FEF}_{\% 25-75}$ değerlerinin saptanmasının, $\mathrm{KOAH}$ hastalığının erken döneminde tespit edilmesinde ve hastaya zamanında bazı önlemlerin alınması konusunda fayda sağlayacağını düşünmekteyiz. Kliniğimize primer akciğer hastalıkları tanısı veya takibi dışında farklı nedenlerle SFT endikasyonu koyduğumuz hastalarımız da başvuru yapmaktadır. Bu nedenle çalışmamızda göğüs hastalıkları polikliniğimize başvuru yaptığında SFT endikasyonu koyulan ve fonksiyonel değerlendirmesinde $\mathrm{FEF}_{\% 25-75}$ düşüklüğü saptanan hastaların polikliniğe başvuru nedenlerini ve $\mathrm{FEF}_{\% 25-75}$ 'in obstrüktif akciğer hastalıklarının erken teşhisine katkısı ve risk faktörlerine yönelik erken müdahalenin önemini vurgulamayı amaçladık. $\mathrm{Bu}$ hastaların değerlendirmesi ile oluşacak sonuçların planlanacak prospektif çalışmalarda takiplerinde y1llar içinde gelişebilecek veya önlenebilecek KOAH hastalığ1 için yeni çalışmalara da 1 ş1k tutabileceğini düşünmekteyiz.

\section{Gereç ve Yöntem}

\section{Hasta seçimi}

01.01.2020 ve 01.04.2021 tarihleri arasinda ESOGÜ göğüs hastalıkları polikliniğine başvuru yapan ve SFT değerlendirmesi yapılan 18 yaş üstü toplam 522 hasta çalışmaya dâhil edildi. Medikal nedenlerden dolayı SFT' ye kooperasyon sağlayamayan hastalar $(n=141)$ çalışma dışı bırakılmıştır. Son olarak, teknik olarak değerlendirilebilir SFT sonuçlarına sahip olan 381 hastanın elektronik tıbbi kayıtları gözden geçirildi ve $\mathrm{FEF}_{\% 25-75}$ değerlerine göre gruplandırıldı (Şekil 1). Polikliniğe başvurusunda SFT endikasyonu olan ancak aşağıdaki üç kriterden en az biri olarak tanımlanan anormal SFT sonuçları olan hastalar; $\mathrm{FEV}_{1} / \mathrm{FVC}$ $<0.7$, FVC tahmin edilen değerin $<\% 80$ 'i ve $\mathrm{FEV}_{1}$ tahmin edilen değerin $<\%$ 80'i olan astım, KOAH veya interstisyel akciğer hastalığ1 gibi altta yatan pulmoner hastalığ 1 olup takip ve tedavi altında olan hastalar 'kontrol başvurusu grubu' olarak siniflandirıldi. 


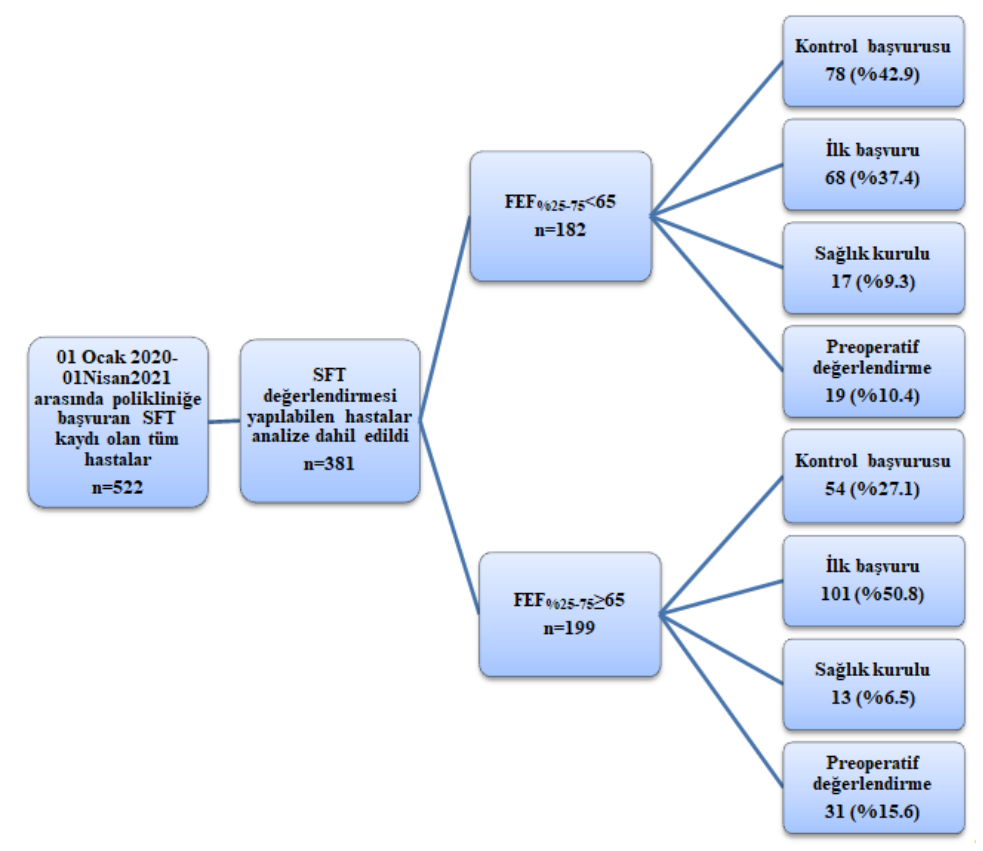

Şekil 1: Çalışma protokolü

SFT: Solunum fonksiyon testi, FEF: Zorunlu ekspiratuar akım

Hastaların demografik özellikleri olarak yaş, cinsiyet, vücut kitle indeksi (VKİ), sigara içme öyküsü, asbest temas öyküsü, geçirilmiş akciğer hastalığı (pnömoni, tüberküloz, pulmoner emboli, pnömotoraks) ve komorbid hastalıklar (arteriyel hipertansiyon, diabetes mellitus, koroner kalp hastalığı (KAH), kronik renal yetmezlik, serebrovasküler hastalık, reflü özofajit, peptik ülser ve gastroösefageal reflü hastalığı gibi gastrik hastalıklar, psikiyatrik hastalıklar ve travma) elektronik kayit sisteminden elde edildi. VKİ, ilk spirometri yapıldığında kilogram cinsinden ağırlığın metre cinsinden yükseklik karesine $\left(\mathrm{kg} / \mathrm{m}^{2}\right)$ bölünmesi ile hesaplandı. VKİ değer aralıklarına göre 4 grupta incelendi; 1 . VKI $<20 ; \quad Z$ Zayıf, $\quad$ VKI $=21-25 ; \quad$ Normal, VKİ=26-30; Fazla kilolu, VKI $>30$ Obez. (8). Sigara içme durumu, sigara içmemiş (yaşam boyu hiç sigara içmemiş), aktif sigara içicisi (halen sigara içmeye devam eden veya 1 yıldan az bir süredir sigarayı bırakmış olan) veya sigarayı bırakmış (önceden sigara içmiş olup 1 yıldan uzun süredir sigara içmeyen) olarak üç grupta değerlendirildi (9). Sigara içimi günde içilen sigara sayısı ile belirlenen paket sayısının sigara içtiği yıl sayısı ile çarpılarak elde edilen 'paket yıllı' ile ölçüldü.
Hastaların öksürük, balgam, nefes darlı̆̆ı, göğüs ağrısı, hemoptizi gibi temel pulmoner semptomları ile halsizlik, kilo kaybı, ateş ve benzeri genel semptomları kayıt edildi.

Hastalar polikliniğe başvuru nedenlerine göre 4 grupta sınıflandırıldı; 1. Illk başvuru grubu; pulmoner veya genel semptomlar nedeniyle ilk başvuru yapan veya bazı klinik problemler nedeniyle konsülte edilen hastalar, 2. Kontrol başvurusu grubu; altta yatan primer akciğer hastalığ1 (astım, KOAH, interstisyel akciğer hastalığ1 (İAH), akciğer kanseri, sarkoidoz, meslek hastalıkları, obstruktif uyku apne sendromu) nedeniyle kontrol ve takip amaçl1 başvuru yapan hastalar, 3. Sağlık kurulu grubu; engelli raporu, durum bildirir rapor ve maluliyet değerlendirmesi amacıyla başvuru yapan sağlık kurulu hastaları, 4. Preoperatif değerlendirme grubu; polikliniğimize ayaktan preoperatif amaçlı konsulte edilen hastalar.

\section{SFT}

SFT Amerikan Toraks Derneği (ATS) kılavuzlarına göre bu konuda eğitim almış SFT teknisyeni tarafından testlerde uygulanan tekrar edilebilirlik ve kabul edilebilirlik değerleriyle, spirometre cihazı (ZAN680 
Ergospirometre) kullanılarak gerçekleştirildi $(10,11)$. Bu çalışma için $\mathrm{FEV}_{1}(\mathrm{~L}), \mathrm{FEV}_{1} \%$, FVC (L), FVC \%, FEV $1 / \mathrm{FVC}, \mathrm{FEF}_{75}(\mathrm{~L})$, $\mathrm{FEF}_{\% 75}, \mathrm{FEF}_{50}(\mathrm{~L}), \mathrm{FEF}_{\% 50}, \mathrm{FEF}_{25}$ (L), $\mathrm{FEF}_{\% 25}$ ve $\mathrm{FEF}_{\% 25-75}$ kayit edildi. Spirometrik veriler, Ulusal Sağlık ve Beslenme İnceleme Anketi (NHANES) standartları kullanılarak tahmin edilen yüzde olarak ifade edildi $(11,12)$. KOAH tanımı, Küresel Girişim (GOLD) k1lavuzlarına uygun olarak, bronkodilatörden sonra $\mathrm{FEV}_{1} / \mathrm{FVC}<0.7$ olarak tanımland $1(2,3)$. $\mathrm{FEF}_{\% 25-75}$ tahmin edilen değerin \%65'inden küçükse 'küçük hava yolu hastalığı' olarak değerlendirildi (13).

$\mathrm{Bu}$ retrospektif çalışma için, ESOGU Etik Kurulu tarafindan 01.06.2021 tarihinde 18 sayı numarası ile etik kurul onayı alındı. Çalışmanın geriye dönük olması nedeniyle bilgilendirilmiş onam formu gerekliliğinden feragat edildi.

\section{Ístatistiksel analiz}

Veri analizleri SPSS version 25.0 (SPSS, Inc., Chicago, IL, USA) paket programı ile yapıldı. Normal dağılım gösteren nicel veriler ShapiroWilk ile analiz edildi. Normal dağılım göstermeyen veriler için medyan, \%25-\%75 percentil değerleri kullanıldı. Normal dağılım göstermeyen sürekli nicel değişkenler Mann-
Whitney U testi ve nitel veriler Kikare testi ile analiz edildi. $\mathrm{p}<0.05$ istatistiksel olarak anlamlı kabul edildi.

\section{Bulgular}

Analize dahil edilen 381 hastanın yaş ortalaması $56.90 \pm 14.09$ (20-88 yaş aralı̆̆ı) idi. Çalışmaya alınan hastaların cinsiyet, sigara içme durumu, asbest maruziyeti, eşlik eden komorbid hastalıkları, geçirilmiş akciğer hastalığı ve başvuru semptom dağılımlarına ilişkin demografik özellikleri Tablo 1'de belirtilmiştir. Hastaların büyük bir kısmında sigara içme ve komorbid hastalık (diyabetes mellitus, arteriyel hipertansiyon, koroner arter hastalığı, serebrovaskuler hastalık, gastroösefageal hastalıklar, malignite ve psikiyatrik hastalıklar) öyküsü mevcut iken daha az bir kısmında geçirilmiş akciğer hastalık öyküsü (tüberküloz, pnömoni, pnömotoraks, pulmoner emboli) mevcuttu. Polikliniğe en sik başvuru semptomu nefes darlığı idi. Çalışmamızın amaçlarından biri olan başvuru nedenleri değerlendirildiğinde hastaların büyük çoğunluğunu göğüs hastalıkları ile ilişkili şikâyetleri olan veya herhangi bir nedenle kliniğimize konsülte edilen veya yönlendirilen ilk başvurusu olan hastalar oluşturmaktaydı (Tablo1).

Tablo 1: Hastaların demografik özellikleri

\begin{tabular}{lc}
\hline Özellikler & Hasta verileri \\
\hline Yaş, (mean \pm SD) & $56.90 \pm 14.09$ \\
\hline Cinsiyet (n, \%) & $184(\% 48.3)$ \\
Kadın & $197(\% 51.7)$ \\
Erkek & $28.58 \pm 5.85$ \\
VKİ (mean \pm SD) & \\
\hline Sigara içme durumu* (n, \%) & $141(\% 37.0)$ \\
Hiç içmemiş & $147(\% 38.6)$ \\
Aktif içici & $90(\% 23.6)$ \\
\hline
\end{tabular}




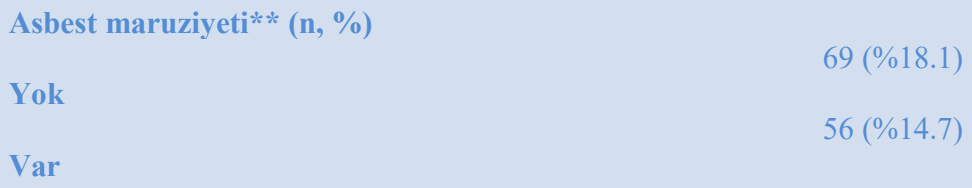

Semptom sıklığı (n, \%)

Öksürük

Balgam

Nefes darlığı

Göğüs ağrısı

Balgam

Polikliniğe başvuru nedenleri (n, \%)

İlk başvuru

VKI: Vücut kitle indeksi

* U̧ç hastaya ait sigara bilgisine ulaşılamadi.

**iki yüz elli altı hastada asbest maruziyet bilgisine ulaşılamadı.

KHH tanimlamasinda yer alan $\mathrm{FEF}_{\% 25-75}<65$ $(n=182)$ ve $\geq 65 \quad(n=199)$ olarak 2 grupta değerlendirildi (Tablo 2 ). İleri yaş ( $\geq 50$ yaş) ile $\mathrm{KHH}$ arasında anlamlı ilişki saptandı. $(\mathrm{p}=0.0001)$. İki grup birbiriyle karşılaştırıldığında cinsiyet açısından fark saptanmad1 $(\mathrm{p}=0.068)$. VKİ ile KHH arasinda istatistiksel olarak anlamlı ilişki saptanmadı $(\mathrm{p}=0.05)$. KHH ile sigara içme durumu arasında istatistiksel olarak anlamlı ilişki gözlendi ( $\mathrm{p}=0.007)$. Aktif sigara içiciliği $\mathrm{KHH}$ grubunda daha yüksek idi. KHH ile komorbid 
hastalık öyküsü arasında anlamlı ilişki mevcuttu $\quad(p=0.018)$ KHH olanlarda komorbid hastalık öyküsü olması $\mathrm{KHH}$ olmayanlara göre daha yüksek oranda saptand. Geçirilmiş akciğer hastalığı olanlarda her iki grup açısından anlamlı farklıl1k saptanmad $1 \quad(\mathrm{p}=0.119)$. Semptom dağılımına bakıldığında nefes darlığı KHH olanlarda, balgam ve hemoptizi ise $\mathrm{KHH}$ olmayanlarda istatistiksel olarak anlaml 1 yüksek idi (sırasiyla $\mathrm{p}=0.0001, \mathrm{p}=0.028$ ve $\mathrm{p}=0.024)$ (Tablo 2).

Tablo 2. $\mathrm{FEF}_{\% 25-75}<65$ ve $\mathrm{FEF}_{\% 25-75} \geq 65$ olan iki grubun demografik özellikleri

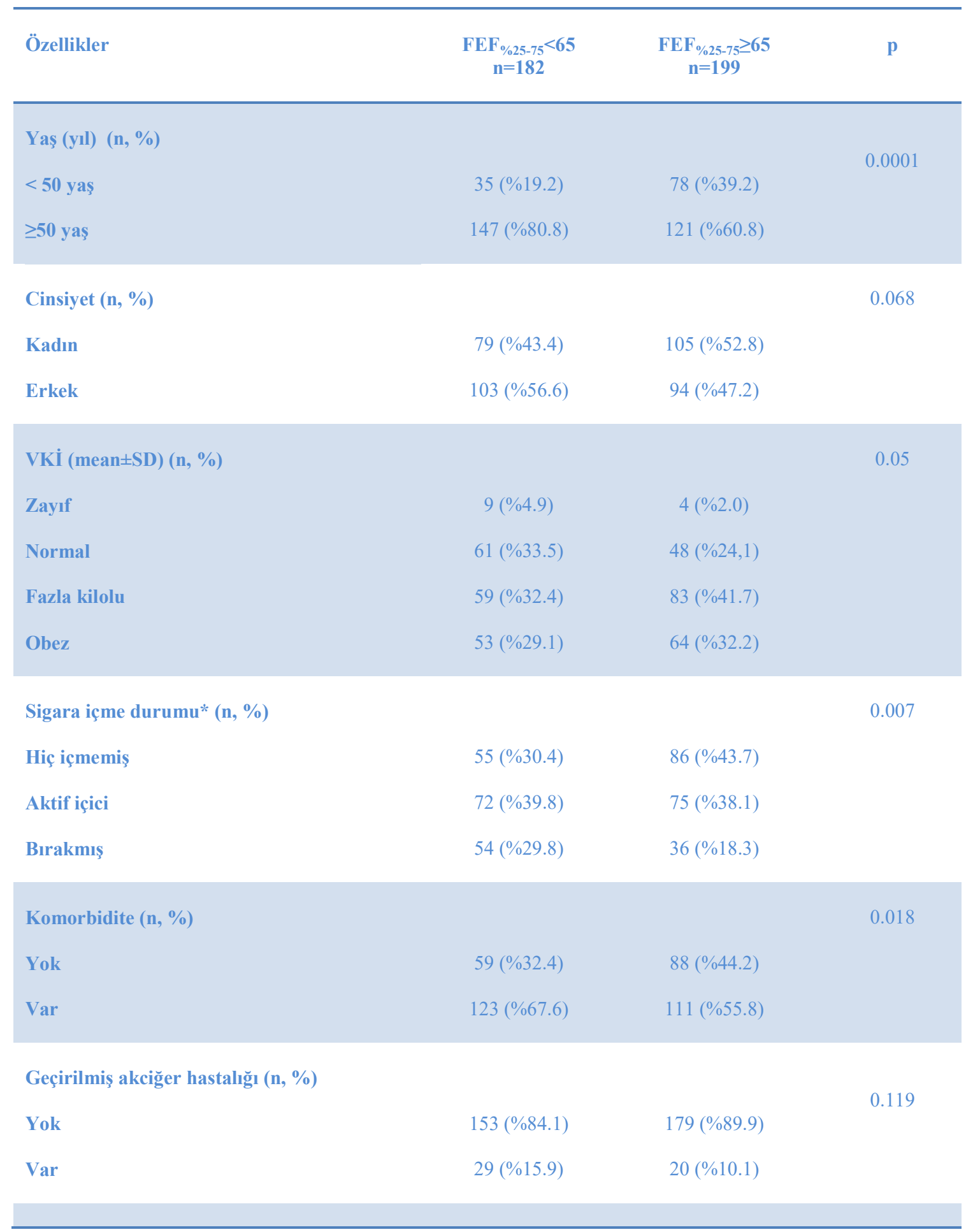




\begin{tabular}{|c|c|c|c|}
\hline \multicolumn{4}{|c|}{ Semptom sıklığı (n, \%) } \\
\hline Öksürük & $72(\% 39.6)$ & $64(\% 32.2)$ & 0.132 \\
\hline Balgam & $48(\% 26.4)$ & $34(\% 17.1)$ & 0.028 \\
\hline Nefes darlığı & $109(\% 59.9)$ & $83(\% 41.7)$ & 0.0001 \\
\hline Göğüs ağrısı & $22(\% 12.1)$ & $15(\% 7.5)$ & 0.185 \\
\hline Hemoptizi & $5(\% 2.7)$ & $0(\% 0.0)$ & 0.024 \\
\hline Genel semptomlar & $20(\% 11.0)$ & $30(\% 15.1)$ & 0.304 \\
\hline
\end{tabular}

FEF: Zorunlu ekspiratuar akım, VKI: Vücut kitle indeksi

* Üç hastaya ait sigara bilgisine ulaşılamad.

Her iki grupta SFT parametrelerine ilişkin ortanca değerler Tablo 3'de gösterilmiştir. $\mathrm{KHH}$ grubunda tüm parametrelerde beklenildiği gibi istatistiksel anlamlı düşüklük saptand $1 \quad(p<0.001)$. KHH ile hastaların polikliniğimize başvuru nedenleri arasındaki ilişki değerlendirildiğinde, KHH saptanmayan hastaların polikliniğe en sik başvuru nedeni farklı nedenlerle polikliniğe ilk başvuru iken (ilk başvuru grubu) $(\mathrm{p}=0.009)$, sağlık kurulu grubu ve preoperatif amaçlı başvuru grupları ile $\mathrm{KHH}$ arasinda istatistiksel olarak anlaml ilişki görülmedi ( $\mathrm{p}=0.409, \mathrm{p}=0.183$ ) (Tablo 4). Kliniğimize kontrol amaçlı başvuru yapan hastaların zaten KHH'nı açıklayacak primer pulmoner patolojileri olması nedeniyle bu grupta KHH görülmesi beklenildiği üzere istatistiksel olarak anlamlı yüksek saptandı $(\mathrm{p}=0.004)$. Kontrol başvurusu grubunu en çok KOAH hastaları oluşturmaktaydı.

Tablo 3: $\mathrm{FEF}_{\% 25-75}<65$ ve $\mathrm{FEF}_{\% 25-75} \geq 65$ olan iki grubun SFT parametreleri

\begin{tabular}{|c|c|c|c|}
\hline Parametre & $\begin{array}{c}\text { FEF }_{\% 25-75}<65 \\
\text { Medyan } \\
\text { 25.-75.persentil }\end{array}$ & $\begin{array}{c}\text { FEF }_{\% 25-75} \geq 65 \\
\text { Medyan } \\
\text { 25.-75.persentil }\end{array}$ & p \\
\hline $\mathrm{FEV}_{1}(\mathrm{~L})$ & $1.6(1.3-2.3)$ & $2.5(2.7-3.2)$ & $<0.001$ \\
\hline $\operatorname{FEV}_{1} \%$ & $66.5(50.0-77.0)$ & $97.0(85.0-106.0)$ & $<0.001$ \\
\hline FVC (L) & $2.3(1.8-3.1)$ & $3.0(2.4-3.8)$ & $<0.001$ \\
\hline FVC \% & $74.0(61.0-86.0)$ & $94.0(81.0-104.0)$ & $<0.001$ \\
\hline $\mathrm{FEV}_{1} / \mathrm{FVC}$ & $72.5(64.0-78.0)$ & $85.0(81.0-88.0)$ & $<0.001$ \\
\hline $\mathrm{FEF}_{75}(\mathrm{~L})$ & $3.1(2.0-4.0)$ & $5.28(4.2-6.6)$ & $<0.001$ \\
\hline $\mathrm{FEF}_{75} \%$ & $50.5(31.8-66.5)$ & $88.0(72.0-101.0)$ & $<0.001$ \\
\hline
\end{tabular}




\begin{tabular}{|c|c|c|c|}
\hline $\mathrm{FEF}_{50}(\mathrm{~L})$ & $1.6(0.9-2.1)$ & $3.6(2.9-4.4)$ & $<0.001$ \\
\hline $\mathrm{FEF}_{50} \%$ & $41.5(26.2-53.0)$ & $89.0(76.0-102.0)$ & $<0.001$ \\
\hline $\mathrm{FEF}_{25}(\mathrm{~L})$ & $0.6(0.4-0.8)$ & $1.2(1.0-1.7)$ & $<0.001$ \\
\hline FEF $_{25} \%$ & $39.0(27.0-50.0)$ & $83.0(70.0-101.0)$ & $<0.001$ \\
\hline $\mathrm{FEF}_{25-75}(\mathrm{~L})$ & $1.3(0.8-1.7)$ & $2.9(2.4-3.6)$ & $<0.001$ \\
\hline $\mathrm{FEF}_{25-75} \%$ & $43.0(28.0-54.0)$ & $88.0(76.0-101.0)$ & $<0.001$ \\
\hline
\end{tabular}

FEF: Zorunlu ekspiratuar akım, $\boldsymbol{F E} \boldsymbol{V}_{1}$ : Birinci saniyede zorlu ekspiratuar hacim, $\boldsymbol{F V C}$ : Zorlu vital kapasite

Tablo 4: $\mathrm{FEF}_{\% 25-75}<65$ ve $\mathrm{FEF}_{\% 25-75} \geq 65$ olan iki grubun polikliniğe başvuru nedenlerinin karşılaştırılması

\begin{tabular}{lccc}
\hline $\begin{array}{l}\text { Polikliniğe başvuru } \\
\text { nedenleri (n, \%) }\end{array}$ & $\begin{array}{c}\mathbf{F E F}_{\% 25-75}<65 \\
\mathbf{n}=\mathbf{1 8 2}\end{array}$ & $\begin{array}{c}\mathbf{F E F}_{\% 25-75 \geq 65} \\
\mathbf{n}=199\end{array}$ & $\mathrm{p}$ \\
\hline IIlk başvuru & $68(\% 37.4)$ & $101(\% 50.8)$ & 0.009 \\
\hline Kontrol başvurusu & $78(\% 42.9)$ & $54(\% 27.1)$ & 0.004 \\
\hline Sağlık kurulu & $17(\% 9.3)$ & $13(\% 6.5)$ & 0.409 \\
\hline Preoperatif değerlendirme & $19(\% 10.4)$ & $31(\% 15.6)$ & 0.183 \\
\hline
\end{tabular}

FEF: Zorunlu ekspiratuar akım

Başvuru nedenlerine göre 4 grupta incelenen hastalar birbiriyle karşılaştırıldığında gruplar arasında yaş, cinsiyet ve VKİ açısından anlamlı farkl111k saptanmad $1 \quad(\mathrm{p}=0.188$, $\mathrm{p}=0.730, \mathrm{p}=0.443$ ) (Tablo 5). Ancak grupları oluşturan hastaların ortanca yaş değeri alındığında kontrol hastalarının ortanca yaşı sağlik kurulu başvurusu yapan hastalara göre istatistiksel olarak anlamlı yüksek saptandı $(\mathrm{p}=0.008)$. Sigara içme durumu ile başvuru nedenleri arasinda istatistiksel olarak anlaml ilişki gözlendi $(\mathrm{p}=0.046)$. Sigara içmeyen, aktif içici veya sigarayı bırakmış olan üç grup da ilk başvuru yapan grupta daha yüksek idi.
Komorbid hastalık öyküsü ile başvuru nedenleri arasında anlamlı ilişki gözlendi. Komorbid hastalık öyküsü ilk başvuru yapan hasta grubunda istatistiksel olarak daha yüksek oranda saptand 1 ( $p=0.034)$. Geçirilmiş akciğer hastalığı öyküsü en yüksek kontrol nedeni ile başvuru yapan hastalarda saptand $(\mathrm{p}=0.002)$. Başvuru semptomları değerlendirildiğinde öksürük, nefes darlığı ve genel semptomlar başvuru nedenleri ile istatistiksel olarak anlamlı ilişkiliydi (sırasıyla $\mathrm{p}=0.001, \mathrm{p}=0.0001, \mathrm{p}=0.027$ ). Öksürük, nefes darlığı ve genel yakınması olanlar en sik ilk başvuru grubunda iken diğer semptomlar 
açısından gruplar arasında anlamlı farklılık (Tablo 5). saptanmad1 $\quad(\mathrm{p}=0.322, \quad \mathrm{p}=0.096, \quad \mathrm{p}=0.343)$

Tablo 5: Başvuru nedenlerine göre değerlendirilen grupların karşılaştırılması

\begin{tabular}{|c|c|c|c|c|c|}
\hline Özellikler & $\begin{array}{c}\text { İlk } \\
\text { başvuru } \\
n=169\end{array}$ & $\begin{array}{c}\text { Kontrol } \\
\text { başvurusu } \\
\mathbf{n}=132\end{array}$ & $\begin{array}{c}\text { Sağlık } \\
\text { kurulu } \\
\mathbf{n}=\mathbf{3 0}\end{array}$ & $\begin{array}{c}\text { Preoperatif } \\
\text { değerlendirme } \\
\mathbf{n}=50\end{array}$ & p \\
\hline Yaş (n, \%) & & & & & 0.188 \\
\hline$<\mathbf{5 0}$ yaş & $53(\% 31.4)$ & $32(\% 24.2)$ & $13(\% 43.3)$ & $15(\% 30.0)$ & \\
\hline$\geq 50$ yaş & $116(\% 68.6)$ & $100(\% 75.8)$ & $17(\% 56.7)$ & $35(\% 70.0)$ & \\
\hline
\end{tabular}

Cinsiyet (n, \%)

0.730

$\begin{array}{llllr}\text { Kadın } & 86(\% 50.9) & 63(\% 47.7) & 14(\% 46.7) & 21(\% 42.0) \\ \text { Erkek } & 83(\% 49.1) & 69(\% 52.3) & 16(\% 53.3) & 29(\% 58.0)\end{array}$

\section{VKi}

Medyan (25.-75.persentil) n (\%)

$28(24-31)$
$6(\% 3.6)$

$28(24-32)$

$26(24-30)$

$26(24-30)$

Zayif

$46(\% 27.2)$

$6(\% 4.5)$

$1(\% 3.3)$

$0(\% 0.0)$

Normal

$66(\% 32.6)$

$39(\% 29.5)$

$13(\% 43.3)$

$11(\% 22.0)$

Fazla kilolu

$51(\% 30.2)$

$43(\% 39.1)$

$10(\% 33.3)$

$23(\% 46.0)$

Obez

$44(\% 33.3)$

$6(\% 20.0)$

$16(\% 32.0)$

Sigara içme durumu* (n, \%)

0.046

$\begin{array}{llllr}\text { Hiç içmemiş } & 61(\% 36.5) & 51(\% 38.9) & 12(\% 40.0) & 17(\% 34.0) \\ \text { Aktif içici } & 66(\% 39.5) & 46(\% 35.1) & 7(\% 23.3) & 28(\% 56.0) \\ \text { Bırakmıș } & 40(\% 24.0) & 34(\% 26.0) & 11(\% 36.7) & 5(\% 10.0)\end{array}$

Bırakmış

$40(\% 24.0)$

$34(\% 26.0)$

Komorbidite (n, \%)

0.034

Yok

$66(\% 39.1)$

$52(\% 39.4)$

$17(\% 56.7)$

$12(\% 24.0)$

Var

$103(\% 60.9)$

$80(\% 60.6)$

$13(\% 43.3)$

$38(\% 76.0)$

Geçirilmiş akciğer hastalığı (n, \%)

0.002

$\begin{array}{lrrrr}\text { Yok } & 157(\% 92.9) & 104(\% 78.8) & 25(\% 83.3) & 46(\% 92.0) \\ \text { Var } & 12(\% 7.1) & 28(\% 21.2) & 5(\% 16.7) & 4(\% 8.0)\end{array}$

Semptom sıklığı (n, \%) 


\begin{tabular}{|c|c|c|c|c|c|}
\hline Öksürük & $77(\% 45.6)$ & $43(\% 32.6)$ & $6(\% 20.0)$ & $10(\% 20.0)$ & 0.001 \\
\hline Balgam & $42(\% 24.9)$ & $22(\% 16.7)$ & $8(\% 26.7)$ & $10(\% 20.0)$ & 0.322 \\
\hline Nefes darlığı & $86(\% 50.9)$ & $78(\% 59.1)$ & $17(\% 56.7)$ & $11(\% 22.0)$ & 0.0001 \\
\hline Göğüs ağrısı & $21(\% 12.4)$ & $9(\% 6.8)$ & $5(\% 16.7)$ & $2(\% 4.0)$ & 0.096 \\
\hline Balgam & $3(\% 1.8)$ & $0(\% 0.0)$ & $1(\% 3.3)$ & $1(\% 2.0)$ & 0.343 \\
\hline Genel semptomlar & $31(\% 18.3)$ & $15(\% 11.4)$ & $1(\% 3.3)$ & $3(\% 6.0)$ & 0.027 \\
\hline
\end{tabular}

VKI: Vücut kitle indeksi

* Üç hastaya ait sigara bilgisine ulaşılamadl.

Hastaların cinsiyet ve sigara içme durumlarına göre yapılan değerlendirmede SFT parametrelerinden $\mathrm{FEV}_{1}(\mathrm{~L}), \mathrm{FEV}_{1} \%$, FVC (L), $\mathrm{FVC} \%, \mathrm{FEV}_{1} / \mathrm{FVC}, \mathrm{FEF}_{75}(\mathrm{~L}), \mathrm{FEF}_{\% 25}$ ve
$\mathrm{FEF}_{\% 25-75}$ değerlerinde istatistiksel anlaml ilişki saptandi $(\mathrm{p}<0.05) . \mathrm{FEF}_{\% 25-75}$ sigara içen erkeklerde kadınlara göre anlamlı düşük saptand $1(\mathrm{p}=0.022)$ (Tablo 6).

Tablo 6: Kadın ve erkek hastalarda sigara içen ve içmeyen gruplarda SFT parametrelerinin karşılaştırılması

\begin{tabular}{|c|c|c|c|c|c|}
\hline \multirow{2}{*}{$\begin{array}{l}\text { SFT } \\
\text { parametreleri }\end{array}$} & \multicolumn{2}{|c|}{ KADIN } & \multicolumn{2}{|c|}{ ERKEK } & \multirow[t]{3}{*}{$\mathbf{p}$} \\
\hline & Sigara + & Sigara- & Sigara + & Sigara- & \\
\hline & $\begin{array}{l}\text { Medyan } \\
\text { 25.-75.persentil }\end{array}$ & $\begin{array}{c}\text { Medyan } \\
\text { 25.-75. persentil }\end{array}$ & $\begin{array}{c}\text { Medyan } \\
\text { 25.-75.persentil }\end{array}$ & $\begin{array}{c}\text { Medyan } \\
\text { 25.-75.persentil }\end{array}$ & \\
\hline $\operatorname{FEV}_{1}(\mathrm{~L})$ & $2.0(1.6-2.5)$ & $1.8(1.5-2.3)$ & $2.4(1.5-2.9)$ & $2.8(2.5-3.5)$ & 0.0001 \\
\hline $\operatorname{FEV}_{1} \%$ & $85,0(72.5-98.5)$ & $87,0(72.0-102.0)$ & $77,0(55.0-91.0)$ & $90,5(75.0-106.0)$ & 0.0001 \\
\hline FVC (L) & $2.5(1.9-3.0)$ & $2.2(1.9-2.6)$ & $3.1(2.5-3.9)$ & $3.6(3.0-4.2)$ & 0.0001 \\
\hline FVC \% & $88,0(74.0-101.0)$ & $86,0(75.0-101.0)$ & $66,0(67.0-94.0)$ & $91,5(77.0-103.0)$ & 0.001 \\
\hline $\mathrm{FEV}_{1} / \mathrm{FVC}$ & $83,0(76.5-86.0)$ & $82,0(79.0-88.0)$ & $76,0(66.0-83.0)$ & $84,0(77.0-87.0)$ & 0.0001 \\
\hline $\mathrm{FEF}_{75}(\mathrm{~L})$ & $3.9(3.0-4.9)$ & $3.9(2.9-4.6)$ & $4.6(2.3-6.2)$ & $6.5(5.6-7.9)$ & 0.0001 \\
\hline $\mathrm{FEF}_{75} \%$ & $71,0(54.0-88.0)$ & $72,0(56.0-89.0)$ & $66,0(35.0-84.0)$ & $91,00(79.5-103.5)$ & 0.117 \\
\hline $\mathrm{FEF}_{50}(\mathrm{~L})$ & $2.6(1.8-3.3)$ & $2.4(1.7-3.3)$ & $2.4(1.3-4.0)$ & $3.8(3.0-4.7)$ & 0.198 \\
\hline $\mathrm{FEF}_{50} \%$ & $70,0(47.0-92.0)$ & $67,0(50.0-87.0)$ & $55,0(32.0-87.0)$ & $88,5(70.0-112.0)$ & 0.112 \\
\hline
\end{tabular}




\begin{tabular}{|c|c|c|c|c|c|}
\hline $\mathrm{FEF}_{25} \%$ & $62,0(46.0-86.5)$ & $74,0(51.0-95.0)$ & $49,0(32.0-81.0)$ & $75,0(55.0-98.0)$ & 0.001 \\
\hline $\mathrm{FEF}_{25-75}(\mathrm{~L})$ & $2.2(1.5-2.8)$ & $2.0(1.5-2.7)$ & $2.0(1.0-3.0)$ & $2.8(2.0-4.0)$ & 0.565 \\
\hline
\end{tabular}

SFT: Solunum fonksiyon testi, $\boldsymbol{F E} \boldsymbol{V}_{1}$ : Birinci saniyede zorlu ekspiratuar hacim, FVC: Zorlu vital kapasite, FEF: Zorunlu ekspiratuar akım

\section{Tartışma}

Çalışmamızda KHH, ileri yaş, aktif sigara içiciliği, komorbid hastalıklar ve nefes darlığ başvuru semptomu ile anlamlı ilişkili iken cinsiyet, VKİ ve geçirilmiş akciğer hastalı̆̆ ile anlamlı ilişkili saptanmad. KHH saptanmayan hastaların polikliniğe en sik ilk başvuru grubunda müracaat ettikleri görüldü. Preoperatif amaçlı başvuru ile sağlık kurulu amaçlı başvuru açısından, iki grup arasında $\mathrm{KHH}$ açısından istatistiksel olarak anlamlı farklılık saptanmadı. Başvuru nedenlerine göre gruplar arasında ileri yaş, cinsiyet ve VKI ile ilişki saptanmazken sigara içme durumu, komorbidite, geçirilmiş akciğer hastalığ olduğu görüldü. Çalışmamız bu sonuçlar doğrultusunda, polikliniğimize obstrüktif hava yolu hastalığ 1 veya parankimal akciğer hastalıkları dışında, KHH'nın belirteci olan $\mathrm{FEF}_{\% 25-75}$ düşüklüğünün erken dönemde hangi başvuru grubunda daha s1k tespit edildiğini yansitmaktadır. $\mathrm{Bu}$ hastalarda $\mathrm{FEF}_{\% 25-75}$ düşüklüğünün erken tespit edilmesinin $\mathrm{KOAH}$ gelişimini önlemek açısından önemi bir kez daha vurgulanmaktadır.

Küçük hava yolu obstrüksiyonu KOAH'ın temel bir özelliğidir. $\mathrm{FEF}_{\% 25-75}$ küçük hava yolu obstrüksiyonunu teşhis etmek için kullanılan FVC' ye bağıml, yüksek değişkenliğe sahip, geniş normal aralığı olan ancak periferik hava yolu obstrüksiyonunun en popüler göstergelerinden biri olup kolayca elde edilebilen solunum fonksiyon parametresidir $(14,15) . \quad \mathrm{FEF}_{\% 25-75}$ obstrüktif hastalığın erken dönemlerinde azalmaya başlar. Restriktif hastalıkların derecesi arttıkça da $\mathrm{FEF}_{\% 25-75}$ değerinde dolaylı azalmalar izlenebilir (16-19). $\quad \mathrm{FEF}_{\% 25-75}$ için tahmin edilen değerin $<75$ veya $<60$ alındığ farklı çalışmalar olmakla birlikte $\mathrm{KHH}$ için $\mathrm{FEF}_{\% 25-}$ $75^{\prime}$ 'in tahmin edilenin $<65$ olarak tanımlandığ 1 çalışmalar da mevcuttur (20-23). Çalışmamızda $\mathrm{FEF}_{\% 25-75}$ için tahmin edilen değerin $<65$ 'i anormal olarak alınmış ve $\mathrm{KHH}$ olarak tanımlanmıştır.

İleri yaş, cinsiyet ve sigara KHH hastalığı için bilinen risk faktörlerindedir. Telenga ve arkadaşlarının çalışmasında ileri yaş ve aktif sigara içiciliğinin akciğer fonksiyon kapasitesindeki azalmayla ilişkili olduğu cinsiyet açısından anlamlı ilişki saptanmadığ 1 rapor edilmiştir. KOAH'lı hastaların hava yolu duvarlarının, sigara içmeyen sağlıklı kontrollere göre önemli ölçüde daha kalın olduğu gösterilmiştir. İleri yaşla birlikte hava yolu duvar kalınlığının azalması gelişirken sigara içenlerde daha çok arttığı görülmüştür ve cinsiyetle anlamlı ilişki saptanmamıştır. Çalışmamızda elli yaş üstü ve aktif sigara içiciliği ile $\mathrm{KHH}$ arasında anlamlı ilişki saptanırken cinsiyet açısından anlamlı ilişki saptanmadı. Bazı çalışmalarda cinsiyet ile fonksiyonel parametreler arasında farklilıklar görülürken bazılarında belirgin farklılık görülmemiştir $(24,25)$. Cohen ve arkadaşlarının fonksiyonel parametreleri değerlendirdiği bir çalışmada ilk kez cinsiyetin astımda küçük hava yolu tutulumunun boyutunda gerçekten önemli bir rol oynayabileceği gösterilmiştir. Erkeklerde 
hava hapsi, kapanma hacmi ve $\mathrm{FEF}_{\% 25-75}$ ile yansıtıldığı gibi, daha büyük derecede bozulmuş küçük hava yolu açıklığı da gösterilmiştir. $\mathrm{Bu}$ da astımda küçük hava yolu boyutlarının erkeklerde kadınlara göre daha önemli bir rol oynadığını düşündürmektedir, yani erkeklerde hava yolu boyutlarında ve kadınlarda hava yolu iltihabı, astımda küçük hava yolu tutulumunun anahtar özelliği olabileceği vurgulanmıştır (26). Bir başka çalışmada ise erkeklerde hava hapsi oranı kadınlara göre önemli ölçüde fazla saptanmıştır (27).

Çalışmamızda sigara içen ve içmeyen erkek ve kadınlar SFT parametreleri açısından birbiriyle karşılaştırıldığında sigara içen erkeklerde kadınlara göre $\mathrm{FEV}_{1}(\mathrm{~L}), \mathrm{FEV}_{1} \%$, FVC (L), FVC \%, FEV $1 /$ FVC, $\mathrm{FEF}_{75}$ (L), $\mathrm{FEF}_{\% 25}$ ve $\mathrm{FEF}_{\% 25-75}$ düzeyinin anlamlı düşük olduğu görülmüştür $\mathrm{Bu}$ durumda erkeklerin bronş ağacı anatomik farklılıkları, kadınlarda daha fazla küçük hava yolu inflamasyonu varken erkeklerde hava hapsinin daha fazla olması ile açıklanabilir. Sigara içmeyen birinci derece akrabalarda sigaradan bağımsız olarak erken başlangıçlı KOAH gelişiminde kontrollere göre daha düşük $\mathrm{FEF}_{\% 25-75}$ ve $\mathrm{FEF}_{25-75} / \mathrm{FVC}$ değerleri saptanmış ve genetik yatkınlık üzerinde de durulmuştur (28). Çalışmamızda kadınlar kendi içinde değerlendirildiğinde sigara içmeyenlerde içenlere göre $\mathrm{FEV}_{1}(\mathrm{~L}), \mathrm{FVC}(\mathrm{L}), \mathrm{FEV}_{1} / \mathrm{FVC}$, $\mathrm{FEF}_{50}(\mathrm{~L}) \mathrm{FEF}_{\% 50}$ ve $\mathrm{FEF}_{25-75}(\mathrm{~L})$ değerinin istatistiksel anlamlı olmasa da düşük saptanmas1 genetik ve hormonal faktörler ile ilgili epidemiyolojik çalışmalara ihtiyaç olduğunu destekleyebilir.

Sigara içmenin KOAH için en önemli risk faktörü olması nedeniyle sigara bırakmanın hastalığın prognozunu etkilemede etkili olduğu da kaçınılmazdır (29). Dolayısıyla polikliniğimize başvuru yapan ve sigara içicisi olan hastalarda KHH'nın tespit edilmesi ile $\mathrm{KOAH}$ gelişimini önlemede sigaranın bırakılmasının ve aralıklı kontrol edilmeleri konusunda bilgilendirmeleri önem arz etmektedir.

Obezitenin küçük hava yolları üzerindeki kronik etkilerini yansıtan az sayıda çalışma mevcuttur (30). Küçük havayolu disfonksiyonunun potansiyel erken göstergesi olan $\mathrm{FEF}_{\% 25-75}$ üzerinde VKİ etkileri değerlendirildiğinde, çalışmalarda ağır sigara içicilerinde VKI'nin $\mathrm{FEF}_{\text {\%25-75ile ilişkili }}$ olduğu (30), $\mathrm{FEF}_{\% 25-75}$ 'in küçük hava yollarındaki düz kas $\alpha$-aktin ile korele olduğu ve hava yolu yeniden şekillenmesi için bir belirteç olduğu (31), yağ ve kas kütlesinin akciğer fonksiyonları ile ilişkili olduğu şeklinde çalışmalar mevcuttur (32). Daha yüksek VKİ seviyelerinin, orta yaşa kadar daha düşük $\mathrm{FEV}_{1} / \mathrm{FVC}$ ve $\mathrm{FEF}_{\% 25-75}$ seviyelerine neden olurken, yaşlanma ile bu etkinin azaldığ1 gösterilmiștir (33). $\mathrm{FEF}_{\% 25-75}$, 16 çalışmanın derlendiği bir meta analizde $(n=13,627)$ aşırı kilolu/obez denekler arasında önemli ölçüde azalırken bu azalmanın çocuklarda anlamlı iken yetişkinlerde anlamlı olmadığı görülmüştür (34). Yine $\mathrm{KOAH}$, obezite ve komorbid hastalıkların prognozdaki önemi bilinmektedir (3). Bizim çalışmamızda tüm hastalar değerlendirildiğinde VKİ ortalamas 28.58 olup 'fazla kilolu grup' ağırlıkta idi. KHH saptanan hastalarda VKİ 'normal grup' daha fazla iken $\mathrm{KHH}$ saptanmayan hastalarda 'fazla kilolu grup' daha sıklıkta idi. Ancak iki grup arasında VKİ açısından istatistiksel olarak anlamlı farklılık saptanmadi. Başvuru nedenlerine göre hastalar karşılaştırıldığında yine VKI açısından anlamlı farklılık saptanmadı. Bunun nedeni KHH saptanan ve saptanmayan hastaların 50 yaş üstü olmasının ağırlıkta olması ve ileri yaşla birlikte VKI'nin de $\mathrm{FEF}_{\% 25-75}$ üzerine etkilerinin azalmas1 olarak açıklanabilir. Komorbid hastalıklar ve prognoza ilişkin olarak yeni prospektif çalışmalar planlanabilir.

$\mathrm{Bu}$ çalışmada, KHH ile ilişkili semptomlara bakıldığında nefes darlığının en önemli belirleyici olduğu ve fizik muayene ve öykü almanın önemi bir kez daha vurgulanmaktadır. Dolayısıyla sigara, hava akımı kısıtlaması olasılığının azalmasıyla ilişkili en etkili faktör iken nefes darlığ 1 da hava akımı sınırlamasının en önemli öngörücü semptomudur. Wiel ve arkadaşlarının yaptığ 1 çalışmada küçük hava yolu disfonksiyonunun bronş hiperreaktivitesinin şiddetini yansıttı gibi astımın klinik ifadesine bağımsız olarak da katkıda bulunduğu belirtilmiştir (35). Çalışmamızda da KHH' da dispnenin önemli 
bir belirleyici semptom olduğu sonucuna varılmış olup balgam ve hemoptizisi olan hastalarda daha çok KHH olmayan başvuru nedenleri saptanmıştır. Ayrıca sigara içen erkeklerde kadınlara göre $\mathrm{FEF}_{\% 25-75}$ anlaml düşük saptanmış olup bu hastaların özellikle sigara biraktırma tedavileri konusunda daha ayrıntılı bilgilendirilmesi gerektiğini vurgulamaktayı.

Küçük havayolu disfonksiyonu olarak tanımlanan ve $\mathrm{FEF}_{\% 25-75}$ değerinin $<60$ alındığ 1 bir çalışmada kontrolsüz astımda inhaler tedavinin küçük hava yollarındaki etkinliği araştırılmıştır. (21). Dolayısıyla $\mathrm{FEF}_{\% 25-75}$ düşüklüğü saptanan astım veya KOAH'l1 hastalarda bu parametreler hastalığın şiddetinin yanında tedavi etkinliğinin değerlendirilmesi amacıyla da kullanılabilir. Küçük hava yolu fonksiyonunun ölçümlerinin, kan eozinofil sayısına ek olarak anti-T2 biyolojik tedavisi için uygun hastaların seçilmesinde fayda sağladığı yönünde de çalışmalar mevcuttur (36). KOAH akut alevlenmelerinde ortaya çıkan küçük hava yollarındaki bozulmanın olduğu hastalarda uygulanan tiotropium tedavisi ile $\mathrm{FEF}_{\% 25-75}$ parametresinde önemli ölçüde iyileşme görüldüğü vurgulanmıştır (37). Bu nedenle poliklinikte tedavi yaklaşımlarına yön çizme yönünde de fayda sağlayabileceği düşünülebilir. Çalışmamızda KHH saptanması beklenen 'kontrol başvurusu grubu' içinde yer alan KOAH, astım ve diğer İAH gibi patolojilerde de hastalığın seyri ve tedavi etkinliğini değerlendirme hakkında bilgi edinilebilir. Biz de KHH olan 182 hastadan 18 astım, $28 \mathrm{KOAH}$ hastasının $\mathrm{FEF}_{\% 25-75}$ değerlerinin seyri ile takipleri ve tedavilerini yeniden gözden geçirme firsatı bulduk.

Çalışmamızın kısıtlayıcı yönleri, retrospektif olması, KOAH hastalarının en az 10 yıllık takiplerinde $\quad \mathrm{KHH}$ seyrinin değerlendirilememesi, altta yatan akciğer hastalığı olan hastaların da çalışma kapsamında yer alması, ileri yaş hastaların fizyolojik değişiklikler nedeniyle çalışmada farklı sonuçlara yol açabilmesi olarak sayılabilir. Rutin SFT ile önemli hava akımı sınırlaması tespit edilebilmesi için küçük hava yollarının $\% 75^{\prime}$ 'inin obstrüksiyonunun gerekli olduğu tahmin edilmektedir. Bu nedenle, bu değerler, kolayca elde edilebilir olsalar da, kendi sınırlamalarına sahiptir ve dikkatle yorumlanmaları gerekir. Ayrica KHH'nın tanınmasının hastalığın sonuçları üzerinde sahip olabileceği potansiyel ile bunu erken tespit edebilecek diğer modalitelere bakmak da gerekebilir.

Sonuç olarak KHH klinisyenler arasında yeterince bilinmediği için poliklinik başvuru nedeni ne olursa olsun obstrüktif akciğer hastalarının erken teşhisinde KHH ile ilişkili risk faktörlerinin bilinmesi önem arz etmektedir. Tanı koyma dışında hastalığın seyri ve tedavi edilmesinde yol gösterici olan $\mathrm{FEF}_{\% 25-75}$ değerinin değerlendirilmesi küçük hava yollarının daha iyi tanınıp erken tespiti ve KHH'nın daha iyi tanınıp hedefe yönelik tedavilerin geliştirilmesi açısından da önem taşımaktadır.

\section{KAYNAKLAR}

1. Park YB, Rhee CK, Yoon HK, et al. COPD clinical practice guideline of the Korean Academy of Tuberculosis and Respiratory Disease: a summary. Tuberc Respir Dis 2018; 81: 261-73.

2. Rabe KF, Hurd S, Anzueto A, et al. Global strategy for the diagnosis, management, and prevention of chronic obstructive pulmonary disease: GOLD executive summary. Am J Respir Crit Care Med. 2007; 176: 532-55.

3. Global strategy for the diagnosis, management, and prevention of Chronic Obstructive Pulmonary Disease (2021 Report). Global initiative for chronic obstructive lung disease. https:// goldcopd.org/ (22.11.2020).

4. Bhatt SP, Balte PP, Schwartz JE, et al. Discriminative accuracy of FEV1: FVC thresholds for COPD-related hospitalization and mortality. JAMA. 2019; 321: 2438-47.

5. Do Sun Kwon YJC, Kim TH, Byun MK, et al. FEF25-75\% Values in Patients with Normal Lung Function Can Predict the Development of Chronic Obstructive Pulmonary Disease. Int J Chron Obstruct Pulmon Dis. 2020; 15: 2913-21.

6. Malerba M, Radaeli A, Olivini A, et al. Association of FEF25-75\% impairment with bronchial hyperresponsiveness and airway inflammation in subjects with asthma-like symptoms. Respiration. 2016; 91: 206-14. 
7. Bird Y, Staines-Orozco H. Pulmonary effects of active smoking and secondhand smoke exposure among adolescent students in Juárez, Mexico. Int $J$ Chron Obstruct Pulmon Dis. 2016; 11: 1459-67.

8. Nuttall FQ. Body mass index: obesity, BMI, and health: a critical review. Nutr Today, 2015; 50: 117-28.

9. Ak G, Metintas M, Metintas S, et al. Lung cancer in individuals less than 50 years of age. Lung. 2007; 185: 279-86.

10. Graham BL, Steenbruggen I, Miller MR, et al. Standardization of spirometry 2019 update. An official American thoracic Society and European respiratory Society technical statement. $\mathrm{Am} \mathrm{J}$ Respir Crit Care Med. 2019; 200: e70-e88.

11. Crapo RO, Morris AH, Gardner RM. Reference spirometric values using techniques and equipment that meet ATS recommendations. $A m$ Rev Respir Dis. 1981; 123: 659-64.

12. Swanney MP, Ruppel G, Enright PL, et al. Using the lower limit of normal for the FEV1/FVC ratio reduces the misclassification of airway obstruction. Thorax. 2008; 63: 1046-51.

13. Ciprandi G, Capasso M, Tosca M, et al. A forced expiratory flow at $25-75 \%$ value $<65 \%$ of predicted should be considered abnormal: a realworld, cross-sectional study. In: Allergy Asthma Proc. 2012;33:e5-8.

14. Deepak D, Prasad A, Atwal SS, et al. Recognition of small airways obstruction in asthma and COPD-the road less travelled. J Clin Diagn Res. 2017; 11: TE01.

15. Hansen JE, Sun XG, Wasserman K. Discriminating measures and normal values for expiratory obstruction. Chest. 2006; 129: 369-77.

16. Johns DP, Walters JA, Walters EH. Diagnosis and early detection of COPD using spirometry. $J$ of Thorac Dis 2014; 6: 1557-69.

17. Olive Jr J, Hyatt RE. Maximal expiratory flow and total respiratory resistance during induced bronchoconstriction in asthmatic subjects. Am Rev Respir Dis 1972; 106: 366-76.

18. Hyatt RE, Scanlon PD, Nakamura $M$. Interpretation of Pulmonary Function Tests. Lippincott Williams \& Wilkins. 2014.

19. Brusasco V, Crapo R, Viegi G. Coming together: the ATS/ERS consensus on clinical pulmonary function testing. Eur Respir J. 2005; 26: 1-2.

20. Terra Filho M, Vargas FS, Cukier A, et al. Forced mid-expiratory flow rate (FEF $25-75 \%$ ): a critical analysis of its value in recognizing diseases of the small airways. Allergol Immunopathol. 1986; 14: 199-203.

21. Hoshino M. Comparison of effectiveness in ciclesonide and fluticasone propionate on small airway function in mild asthma. Allergol Int. 2010; 59: 59-66.

22. Uppala R, Kaenpugdee P, Srisutthikamol S, et al. Assessment of small airway function and reversibility in symptom-controlled asthma in pediatric patients. Asian Pac J Allergy Immunol. 2019; 37: 25-9.

23. Lin SP, Shih SC, Chuang CK, et al. Characterization of pulmonary function impairments in patients with mucopolysaccharidoses - changes with age and treatment. Pediatr Pulmonol. 2014; 49: 277-84.
24. Stanojevic S, Wade A, Cole TJ, et al. Spirometry centile charts for young Caucasian children: the Asthma UK Collaborative Initiative. Am J Respir Crit Care Med. 2009; 180(6): 547-52.

25. Stanojevic S, Wade A, Stocks J, et al. Reference ranges for spirometry across all ages: a new approach. Am J Respir Crit Care Med. 2008; 177: 253-60.

26. Cohen J, Douma WR, Ten Hacken NHT. et al. Physiology of the small airways: A gender difference?. Respir Med 2008; 102: 1264-71.

27. Hashimoto M, Tate E, Watarai J, et al. Air trapping on computed tomography images of healthy individuals: effects of respiration and body mass index. Clin Radiol. 2006; 61: 883-7.

28. DeMeo DL, Carey VJ, Chapman HA, et al. Familial aggregation of FEF25-75 and FEF2575/FVC in families with severe, early onset COPD. Thorax. 2004; 59: 396-400.

29. Andevoorde J, Verbanck S, Gijssels L, et al. Early detection of COPD: a case finding study in general practice. Respir Med. 2007; 101: 525-30.

30. Abston E, Comellas A, Reed RM, et al. Higher $\mathrm{BMI}$ is associated with higher expiratory airflow normalised for lung volume (FEF25-75/FVC) in COPD. BMJ Open Respir Res. 2017; 4: e000231.

31. Bergeron $C$, Hauber HP, Gotfried $M$, et al. Evidence of remodeling in peripheral airways of patients with mild to moderate asthma: effect of hydrofluoroalkane-flunisolide. $J$ Allergy Clin Immunol. 2005; 116: 983-9.

32. Tsao YC, Lee YY, Chen J. et al. Gender-and agespecific associations between body fat composition and C-reactive protein with lung function: a cross-sectional study. Sci Rep. 2019; 9: $1-9$.

33. Probst-Hensch N, Jeong A, Stolz D, et al. Causal Effects of Body Mass Index on Airflow Obstruction and Forced Mid-Expiratory Flow: A Mendelian Randomization Study Taking Interactions and Age-Specific Instruments Into Consideration Toward a Life Course Perspective. Front Public Health. 2021; 11:584955.

34. Forno E, Han YY, Mullen J, et al. Overweight, obesity, and lung function in children and adultsa meta-analysis. J Allergy Clin Immunol Pract. 2018; 6: 570-81. e10.

35. Van der Wiel E, Postma DS, Van Der Molen T, et al. Effects of small airway dysfunction on the clinical expression of asthma: a focus on asthma symptoms and bronchial hyper-responsiveness. Allergy. 2014; 69: 1681-8.

36. Abdo M, Watz H, Veith V, et al. Small airway dysfunction as predictor and marker for clinical response to biological therapy in severe eosinophilic asthma: a longitudinal observational study. Respir Res. 2020; 21: 1-7.

37. Incorvaia $\mathrm{C}$, Riario-Sforza GG, Pravettoni $\mathrm{C}$, et al. Impairment of small airways in COPD patients with frequent exacerbations and effects of treatment with tiotropium. Int $J$ Chron Obstruct Pulmon Dis. 2008; 3: 123. 